\title{
Discursos territoriales contrapuestos en el siglo XXI: el caso de Chile-Perú desde la geopolítica crítica
}

\author{
Territorial discourses opposed in the 21st century: \\ The case of the Chile-Peru relationship from a critical \\ geopolitics perspective
}

Lester Cabrera a* (iD https://orcid.org/0000-0003-0307-1528
Recibido el 3 de octubre de 2018.

Aceptado el 10 de diciembre de 2018.

Publicado el 19 de diciembre de 2018.

*Autor para correspondencia: Lester Cabrera, correo electrónico: lecabrerafl@flacso.edu.ec
Esta obra está protegida bajo una Licencia Creative Commons Atribución-NoComercial 4.0 Internacional.

\author{
${ }^{a}$ Facultad Latinoamericana de Ciencias Sociales, Departamento de Estudios Internacionales y \\ Comunicación, Quito, Ecuador, correo electrónico: lecabrerafl@flacso.edu.ec
}

\section{Resumen}

El presente artículo tiene por objetivo comprender, desde la visión de la geopolítica crítica, como los discursos de los conflictos territoriales del siglo xxi entre Chile y Perú, han sido representados por cada una de las partes, al tiempo que se establecen elementos subyacentes que van más allá de las concepciones oficiales emitidas por los Estados. Para lograrlo, se considera un acercamiento teórico-conceptual de la noción de territorio desde la disciplina mencionada, y así establecer cómo el territorio ha sido considerado mayormente como un aspecto conflictivo en la historia bilateral, demostrándose en los últimos años en la contraposición por la frontera marítima y en el denominado "triángulo terrestre". Se concluye que los conflictos territoriales son solo una muestra de un problema más estructural en la relación entre ambos países, al tiempo que el discurso territorial es utilizado como mecanismo para maximizar las diferencias y minimizar las similitudes.

Palabras clave: geopolítica crítica, Chile, Perú, territorio, discurso.

\begin{abstract}
The objective of this article is to understand, from the perspective of critical geopolitics, how the discourses of territorial conflicts between Chile and Peru in the 21st century have been represented by each of the parties, while at the same time establishing underlying elements that they go beyond the official conceptions issued by the States. To obtain this, a theoretical-conceptual approach to the notion of territory is considered from the mentioned discipline, and thus establish how the territory has been considered most-
\end{abstract}

CÓMO CITAR: Cabrera, L. (2018). Discursos territoriales contrapuestos en el siglo XXI: el caso de Chile-Perú desde la geopolítica crítica [Territorial discourses opposed in the 21st century: The case of the Chile-Peru relationship from a critical geopolitics perspective]. Estudios Fronterizos, 19, e021. doi:https://doi.org/10.21670/ref.1821021 
ly as a conflictive aspect in bilateral history, demonstrated in recent years in the territorial oppositions made by the maritime border and in the so-called "terrestrial triangle". It is concluded that the territorial conflicts are only a sample of a more structural problem in the relationship between both countries, while the territorial discourse is used to maximize the differences and minimize the similarities.

Keywords: critical geopolitics, Chile, Peru, territory, discourse.

\section{Introducción}

¿Cómo se han representado, a través de la visión de la geopolítica crítica, algunos de los discursos vinculados a conflictos territoriales en la relación bilateral Chile-Perú, ${ }^{1}$ en lo que va del siglo xxi? El presente artículo tiene por objetivo responder a la interrogante planteada. Pero sin perjuicio de un subsecuente desarrollo de los diferentes tópicos que involucra dicha pregunta, desde un punto de vista metodológico, resulta adecuado dar una respuesta de carácter introductorio y simple. En primer lugar, la relación bilateral entre Chile y Perú, desde una visión histórica y política, ha estado cargada de visiones opuestas como de intereses contrapuestos, especialmente desde el fin de la Guerra del Pacífico o del Salitre (1879-1883). Aquella concepción, si bien se ha matizado en algunos sentidos, mantiene elementos estructurales de desconfianza entre las partes, lo que dificulta un entendimiento que vaya más allá de las relaciones comerciales, específicamente en lo que va del siglo xxı. Siendo así, las construcciones discursivas sobre determinados puntos, como lo fue la controversia sostenida por la delimitación marítima y la posición sobre el denominado "triángulo terrestre", evidencian que más allá de los problemas puntuales, las diferencias se manifiestan en elementos que se encuentran subyacentes al discurso oficial esbozado tanto por Chile como por Perú. Así, pese a que ambos puntos conflictivos tienen como común denominador el territorio, la naturaleza de los mismos es diferente, principalmente como consecuencia de los elementos discursivos que construyen la representación de aquellos espacios territoriales.

Y como consecuencia de la existencia de aquellos aspectos subyacentes, los cuales es posible concebirlos en manifestaciones discursivas que, de alguna u otra forma son parte de la constitución de identidad por ambas partes, es que la visión que ofrece la geopolítica crítica, permite visualizar y explicar el fenómeno mencionado. Lo anterior adquiere una mayor fuerza, tomando en cuenta el hecho de que la totalidad de los aspectos señalados donde se manifiestan los discursos contrapuestos, son parte de un relato que vincula elementos territoriales; por lo tanto, a través de una comprensión más amplia de los espacios territoriales, resulta válido comprender el valor que el territorio posee desde una óptica en torno a la generación y construcción de una identidad, como también, para visualizar el fenómeno conflictivo desde un punto de vista más holístico y no únicamente circunscrito a una concepción eminentemente jurídica, siendo esta la que mayormente se refleja en los conflictos territoriales que ambos países han sostenido en lo que va del siglo. Esto último además es explicado producto del proceso internacional llevado por ambos países desde el año 2008,

\footnotetext{
${ }^{1}$ En el presente artículo, se toma el orden Chile-Perú, solamente por una alusión de orden alfabético.
} 
cuando Perú interpuso una demanda en contra de Chile en la Corte Internacional de Justicia (CIJ), con el objetivo de definir el límite marítimo entre ambos países.

El objeto de estudio del presente artículo se enfoca en analizar y explicar cómo Chile y Perú conciben ciertas visiones discursivas territoriales contrapuestas, desde la óptica que establece la geopolítica crítica, tomando como casos de estudio las controversias señaladas en su momento. $\mathrm{Al}$ respecto, si bien los elementos metodológicos que se circunscriben a la disciplina mencionada aún se encuentran en pleno debate, lo cierto es que la incorporación de elementos que son válidos en la interpretación de la importancia territorial, como por ejemplo el discurso y los símbolos, hacen que la visión en torno al objeto de estudio se aleje de la explicación tradicional, obteniendo con ello una perspectiva diferente para comprender la influencia de los elementos que subyacen en los conflictos mencionados. Pero sin perjuicio de lo anterior, cabe señalar que el principal valor de la geopolítica crítica para el presente trabajo, radica en una nueva comprensión en lo relativo a la representación del territorio entre Chile y Perú, países en los que las problemáticas de este tipo, se han constituido en una buena parte de su historia bilateral; pero que dichos fenómenos han sido analizados y explicados desde una perspectiva positivista, dándole un valor absoluto al territorio y sin considerar aquellos elementos que poseen una cualidad más subjetiva.

Los discursos planteados, si bien se extraen de los conflictos territoriales señalados en su momento entre ambos países, el origen de los mismos proviene desde la academia. En este sentido, la concepción de la geopolítica crítica que se considerará, será la relacionada con la denominada geopolítica formal, visión que toma la perspectiva discursiva derivada de universidades y centros de pensamiento, para la conformación de una representación territorial. En este sentido, los discursos si bien se vinculan con una concepción oficializada por ambos Estados, la relación entre la historia conflictiva y las nuevas disputas territoriales, se aprecian de manera más clara desde la perspectiva que otorga la academia. Esto, producto de que, dentro del discurso de representación territorial desde la geopolítica formal, se efectúa una relación entre aquellos elementos estructurales conflictivos, como lo son la historia del siglo xix y otras disputas que se asociaron a elementos culturales, y la concepción hacia la contraparte, en la mayoría de las veces, tomando en cuenta la influencia del relato histórico bilateral.

El trabajo concluye en que pese a que se traten y analicen los elementos que son derivados de la conflictividad territorial entre ambos países, aún existen una serie de aspectos subyacentes en la relación bilateral que se derivan tanto de las desavenencias territoriales, como también de la influencia de un discurso geopolítico conflictivo. Siendo así, los aspectos subyacentes que se extraen de este discurso, son los principales elementos que deben ser considerados para lograr superar un problema estructural entre ambos países, con el fin de maximizar los procesos positivos y minimizar los segmentos negativos de la relación bilateral.

\section{El valor de la geopolítica crítica: Territorio y discursos}

Cuando se tocan temáticas conflictivas en el mundo, existe la mala tendencia, tanto por analistas, reporteros e incluso académicos, de señalar que dicha problemática responde a una cualidad geopolítica o, en su defecto, es un fenómeno geopolítico. Si bien es cierto que aquello puede tener algún grado de relación con la disciplina, 
es una muestra tanto del abuso que se hace del concepto, como también del desconocimiento que se tiene del mismo, debido a que fenómenos relacionados con disputas territoriales, recursos naturales, problemas económicos, e incluso cuando se emplean los medios militares de un país, caben en la concepción de "problema geopolítico", lo cual no necesariamente es así (Kelly, 2016). Por lo tanto, para hablar de geopolítica, se requiere una pequeña conceptualización, con el único objetivo de determinar qué es lo que se entiende y, tal vez más importante aún, lo que no se entiende por geopolítica, desde un punto de vista disciplinario.

A grandes rasgos, la geopolítica como disciplina puede dividirse en dos grandes conjuntos, pese a que existan diferentes áreas dentro de cada uno de ellos: la geopolítica clásica y la geopolítica crítica. La perspectiva clásica deviene de un pensamiento eminentemente de carácter positivista, el cual tuvo sus inicios como tal a fines del siglo XIx, principalmente como consecuencia de la influencia que el darwinismo social generó en aquellos tiempos. Sin embargo, su expresión como disciplina se logró a mediados de la primera mitad del siglo xx, especialmente en la manera de visualizar el mundo, generando con ello una cosmovisión donde el Estado tenía un rol preponderante. En este sentido, se estableció un vínculo entre el Estado y su potencial de desarrollo por un lado, y el contexto geográfico y político que lo rodeaba por otro (Cuéllar, 2012). No obstante, la utilización de la geopolítica como una forma de justificar determinados planes con fines ideológicos y raciales, siendo el proyecto de expansión territorial nazi la principal muestra de aquella visión, desacreditó a la disciplina como una rama académica objetiva. No fue sino hasta la década de los setenta, en que académicos como Yves Lacoste, o funcionarios como Zbigniew Brzezinski, volvieron a colocar en el debate la importancia que tiene el estudio de la geopolítica, para poder comprender y explicar una serie de fenómenos mundiales ${ }^{2}$ (Cohen, 2015; Lacoste, 2011). Aunque cabe destacar que en América Latina, el estudio y desarrollo de lineamientos geopolíticos tuvo una alta relevancia después del fin de la Segunda Guerra Mundial, lo que fue impulsado por los estamentos militares en sus cursos de especialización y perfeccionamiento (Cabrera, 2017; Child, 1979; Dodds, 1993).

A la par con los cambios de paradigma en las ciencias sociales, donde se comenzó a privilegiar una visión más cercana al interpretativismo, en directa contraposición con el positivismo, es que la geopolítica comenzó a ser vista desde otros ángulos y puntos de vista. Así, se le comenzó a otorgar al discurso, la facultad de establecer tanto realidades sociales como geográficas, en lo relativo a la interpretación de un lugar o incluso un Estado. Sobre aquella visión, es que los trabajos de Simon Dalby (1990), como también las perspectivas de Gearoid O’Tuathail y John Agnew (1992), adquieren una importancia gravitante a la hora de reconceptualizar los elementos que son propios de la geopolítica, partiendo de una concepción crítica en torno a la utilización de la misma. Es decir, tomando en consideración tanto el contexto en que se emite el discurso geopolítico, los mismos actores que lo reproducen, e incluso la finalidad del mismo, es posible evidenciar que la concepción clásica de la geopolítica puede ser observada desde una óptica imperialista, racista y clasista (O'Tuathail, 1996). Dicha perspectiva, que también es parte de una forma de interpretar una realidad

\footnotetext{
${ }^{2}$ Sin embargo, la concepción de la geopolítica desde la escuela francesa, tuvo un desarrollo mucho mayor, conceptual y teóricamente hablando, en comparación a la noción estadounidense por aquellos años. Un ejemplo es que desde la perspectiva de este último país, se asociaba directamente a la geopolítica con la teoría realista, pese a que pueden tener un posicionamiento epistémico diferente (Kelly, 2016).
} 
geopolítica, es propia de la geopolítica crítica, cuyos inicios epistémicos si bien son parte del debate dado desde fines de la década de los setenta y comienzos de los ochenta, su reconocimiento como área de estudio se da como tal en la década de los noventa (Dodds, Kuus y Sharp, 2013).

Pese a lo mencionado, uno de los elementos clave que es parte del pensamiento crítico de la disciplina, es el hecho de establecer, dentro de una eventual explicación en torno a un fenómeno o proceso, diferentes aspectos que son subyacentes a las realidades que evidencia el pensamiento positivista de la perspectiva clásica de la geopolítica. En este sentido, para poder entender el valor del discurso geopolítico, es necesario evidenciar cuales son aquellos elementos subyacentes detrás del discurso, o en su defecto, cuales son los aspectos que influyen en la elaboración y creación de dicho discurso geopolítico. Este punto es uno de los principales diferenciadores entre el pensamiento clásico y crítico de la geopolítica, tomando en cuenta que es a través del discurso donde se crean realidades socialmente aceptadas y legitimadas, sobre elementos que, en un primer momento, son considerados como objetivos, como por ejemplo el territorio y la relación con el Estado (Kelly, 2006).

Como se mencionó en su momento, el discurso en lo relativo a la interpretación y representación de determinados lugares y espacios, es uno de los principales objetos de estudio de la geopolítica crítica. Pero sin perjuicio de lo planteado, el discurso geopolítico no puede ser comprendido como un discurso absoluto o único; es decir, el hecho de enfocar una explicación sobre la base de un discurso cualquiera, no hace que el fenómeno sea geopolítico como tal. Para que exista una representación discursiva en el plano geopolítico, dicho discurso debe estar asociado a un elemento territorial, espacial o en torno a un lugar determinado. Si aquello no sucede, se cae en un relativismo que, de acuerdo a Martin Müller (2008), plantea así mismo el principal desafío de la geopolítica crítica: establecer la territorialidad del discurso geopolítico, en conjunto con sus elementos subyacentes.

Así, a juicio de John Agnew, el territorio como tal no puede ser correctamente entendido en su complejidad si solamente se visualiza como un algo homogéneo y absoluto, sino que debe comprenderse como un aspecto que posee diferentes singularidades (Agnew, 1994). El problema deviene en que dentro del plano de representación del territorio a nivel internacional, las singularidades territoriales se acoplan a la concepción estatal unitaria, manifestándose esto en el plano de la política exterior. Por lo tanto, la influencia de otros elementos que no sean parte de aquella lógica homogénea y centralista, quedan minimizados, incluso dentro de otros actores que son representativos de la figura del Estado, pero que evocan a dicho actor dentro de una lógica simbólica o cultural según Hassner (2006-2007). Al respecto, el mencionado autor señala que son los aspectos culturales y simbólicos, los que mayormente determinan aquellos discursos de singularidad de los espacios nacionales o estatales. Esto es relevante para la visión de la geopolítica crítica, debido a que uno de los principales objetivos de dicha disciplina, descansa en la necesidad de conocer los elementos que ilustran y dieron origen a los discursos identitarios a nivel nacional y estatal, para así establecer una parte de los intereses que dichos elementos discursivos poseen, tomando en consideración la vinculación con un espacio territorial determinado.

En relación con la influencia de los relatos en la generación de identidades, especialmente en el nivel nacional y estatal, la representación discursiva del territorio juega un papel clave a la hora de comprender la mantención de dicho discurso o, 
en su defecto, el establecimiento de determinadas imágenes con respecto a otros actores que también son parte de la concepción de Estado. El discurso desde una óptica territorial, además de señalar una suerte de "realidad" geográfica, también posee una serie de elementos subyacentes que son parte de los intereses de los actores que elaboraron dicho discurso, al tiempo que es capaz de ponderar amenazas como imágenes de una serie de actores y procesos, localizados dentro de una dimensión tanto nacional como internacional, dentro de un imaginario determinado. Sobre estos elementos, es que el discurso y el territorio adquieren su vinculación: por un lado la interpretación del discurso territorial; y por otro la ampliación de la perspectiva del territorio, al incorporar diferentes actores y procesos que modifican un punto de vista absoluto y rígido del mismo (Agnew, 1994).

Siendo así, es posible señalar que la interpretación discursiva al territorio, lleva consigo una valoración y representación del mismo, tanto en términos de amenaza como también de oportunidades, frente a otros países como también a diferentes actores del sistema internacional (O'Tuathail y Dalby, 1998). No obstante, el hecho de considerar al territorio dentro de una lógica discursiva, también incluye la valoración de un relato histórico y cultural que se ha efectuado del mismo. En este sentido, los aspectos discursivos llevan a una interpretación que va más allá de la noción positivista de catalogar a un espacio territorial como "estratégico": el territorio también pasa a ser parte de un imaginario social que puede ser parte de una deconstrucción, o incluso como parte de un relato clave dentro de la construcción de identidades nacionales, estatales o incluso traspasando los límites internacionales del Estado (Hassner, 2006-2007).

$\mathrm{Y}$ en conjunto con lo anterior, es que el discurso permite visibilizar otros actores y procesos que se vinculan al territorio, y que a su vez generan cambio en su interpretación. Por ejemplo, los territorios que son considerados como parte de un espacio fronterizo, no pueden ser comprendidos cabalmente si no se tiene una noción en torno a los elementos que lo van permeando y, por ende, modificando en su significación (Anderson, 1996). Pero además, la representación geopolítica de los espacios territoriales da cuenta de los actores que intervienen dentro de la generación de aquel discurso, sus intereses, el contexto en el cual fue elaborado, como también su perspectiva en torno sobre si dicho discurso encuentra una respuesta, ya sea positiva o negativa, de parte de otros actores que poseen un grado de interés sobre aquel espacio territorial (Kelly, 2016). Estos elementos se asocian a la concepción crítica de la geopolítica, debido a que la visión clásica supone, en términos generales, una perspectiva absoluta del territorio, tomando como principal unidad de análisis al Estado y minimizando el rol del discurso u otras formas que actúan en la interpretación de un espacio territorial.

Otro de los aspectos que se destacan en la utilización del enfoque crítico de la geopolítica por sobre el clásico, además de ir en contra de la concepción absoluta del territorio del último enfoque señalado, está en el hecho de que producto de la visión que otorga la geopolítica crítica, los planteamientos clásicos de la disciplina pueden ser entendidos y explicados desde una mejor perspectiva, especialmente en lo relativo a la identificación de actores y procesos. Lo anterior se genera como producto de que a través de la visualización de aquellos elementos que se encuentran subyacentes en el discurso geopolítico clásico, es posible evidenciar tanto los objetivos como las motivaciones que hay detrás de aquel discurso. Por eso, la visualización y análisis de un proceso territorial, si bien puede establecer premisas geopolíticas desde el punto 
de vista clásico de características positivistas, las cuales ayudan a su entendimiento, aquella forma posee un sesgo y diferentes limitantes que, como consecuencia del uso de la concepción crítica de la geopolítica, es posible apreciarlas y vincularlas en la consecuente explicación del proceso territorial en cuestión. Es por eso que, si bien existen algunos autores que establecen diferencias, en muchos casos que a su juicio se consideran insalvables entre aquellas dos vertientes de la geopolítica, lo cierto es que más allá de las variaciones epistémicas, ambas ramas son complementarias a la hora de observar, analizar y explicar un fenómeno territorial, especialmente si este posee características conflictivas (Cairo y Lois, 2014; Kelly, 2006).

Por lo tanto, la representación sobre un territorio y el discurso que se establezca sobre dicho aspecto, están totalmente vinculados, debido a que es producto del discurso sobre el cual se construye una representación territorial. Siendo así, la representación geopolítica del territorio se relaciona con la forma en que un grupo de actores, ya sean tomadores de decisión en el ámbito de la política exterior, académicos o incluso parte de la sociedad (como se visualiza en la división entre geopolítica práctica, formal y popular), reflejan sus intereses sobre un espacio territorial determinado y, al mismo tiempo, poseen un espacio de influencia dentro de la conformación de la agenda, especialmente en el plano internacional (O'Tuathail y Dalby, 1998). Y en dicha representación, intervienen tanto el contexto, la historia, la cultura, como los procesos que pudiesen afectar, tanto positiva como negativamente, aquella interpretación. En este punto, se sostiene el hecho de que la representación de un territorio, dentro del plano de la geopolítica, tiene principalmente un impacto en el ámbito internacional, considerando que un discurso territorial nacional o estatal, puede ser interpretado como parte de un acto de acercamiento o de amenaza, de acuerdo a la interpretación realizada en otros espacios, fundamentalmente de índole estatal. Lo anterior refuerza la cualidad subjetiva del territorio y la forma en cómo se representa, lo que decanta a su vez en imágenes y una cosmovisión preconcebida, de acuerdo a diferentes intereses, pero que no necesariamente representa una realidad mayoritariamente aceptada.

La geopolítica crítica no solamente ayuda a la comprensión más amplia y holística de un fenómeno territorial conflictivo a través de la inclusión de elementos que, desde el enfoque clásico, no poseen una prioridad; sino que además, permite la apreciación de aspectos que si bien pueden ser concebidos como la base del conflicto desde un discurso oficial, no lo son si el proceso es observado desde la importancia que los elementos en disputa representan para ámbitos como la identidad o una determinada cultura. A raíz de lo anterior, los conflictos territoriales entre países que han compartido una historia relacionada a enfrentamientos bélicos y las consecuencias negativas que aquello genera, es posible analizarlos y explicarlos desde una óptica que identifique los problemas más estructurales, dejando a un lado los elementos coyunturales o que buscan una solución parcial al problema. Dicho enfoque es posible aplicarlo a la relación entre Chile y Perú, especialmente en lo que va del siglo xxi.

\section{El territorio como conflicto en la relación Chile-Perú}

Uno de los puntos centrales y que, de acuerdo con autores tales como José Rodríguez (2004) y Daniel Parodi (2014), se ha establecido una agenda dentro de la relación entre Chile y Perú, que se centra en la confrontación de posiciones, especialmente 
cuando se tiene en controversia un tema territorial. Aquel aspecto, si bien puede ser un elemento que sea común cuando hay países que han tenido guerras por determinados territorios, lo cierto es que los ingredientes culturales juegan un papel central en la mantención de un relato, especialmente cuando no se han realizado esfuerzos sistemáticos para solucionar dicho problema (Hassner, 2006-2007), situación que se presenta en la relación bilateral señalada.

Pero para poder comprender el contexto previo en el cual ambos países se encontraban al momento de inicio de los problemas territoriales en el siglo xxI, conviene señalar y explicar la forma en que se vinculaban Chile y Perú, especialmente a fines de la década de los noventa, tomando como uno de los puntos clave para la comprensión de la relación bilateral, la suscripción en el año 1999 de la denominada Acta de Ejecución de los temas pendientes, derivados del Tratado de Lima de 1929. ${ }^{3}$ $\mathrm{Y}$ pese a que ambos países priorizaron dicho acercamiento dentro de los diferentes tópicos de la relación bilateral, su negociación no solamente estuvo exenta de problemas, sino que además tuvo una significancia menor, debido tanto a los tiempos políticos como también a los propios tópicos tratados. No obstante, su aprobación por ambos países fue considerada un hecho histórico en las relaciones bilaterales. ${ }^{4}$ Y pese a que finalmente se llegó al objetivo en el cumplimiento de los elementos pendientes entre ambos países, después de 70 años de suscrito el Tratado de Lima, y que se esperaba con ello una nueva faceta de las relaciones, la realidad fue otra. En el siglo XXI, ambos países se han visto enfrentados por discrepancias, especialmente en el ámbito territorial, que dejó de lado las eventuales expectativas logradas a fines del siglo xx. Sin embargo, las mencionadas "expectativas" tenían una base de comprensión y tratamiento dudosa, por ambos lados de la relación.

Desde la perspectiva chilena, la concepción en torno a la negociación de un tema territorial con Perú, pese a que era un aspecto pendiente, tampoco representó un elemento central en la misma, debido a las prioridades de la política exterior chilena por aquellos años en términos generales. Así, si bien la composición de la política exterior, especialmente en la segunda mitad de la década de los año noventa, tuvo un refuerzo en la adopción de acuerdos comerciales con otros países, priorizando dicho tipo de vinculación por sobre los temas más políticos (Fermandois, 2004), también la agenda estuvo marcada por acontecimientos de carácter coyuntural, como lo fue el arresto de Augusto Pinochet en Londres. Aquel suceso, a juicio de Paz Milet (2012), ayudó a "pinochetizar" la política exterior a fines de la mencionada década, justo en los

\footnotetext{
${ }^{3}$ El Tratado de Lima de 1929, en conjunto con su Protocolo Complementario del mismo año, fue el instrumento jurídico que definió, después de 50 años de iniciada la Guerra del Pacífico (1879-1883), que Chile y Perú tuvieran una frontera común. Por lo tanto, dicho tratado se considera como el elemento central para la definición de la actual frontera terrestre entre ambos países (Tratado de Lima y su Protocolo Complementario, 1929).

${ }^{4}$ En su discurso oficial para la suscripción de la mencionada Acta de Ejecución, el entonces Canciller de Perú de la época, Fernando de Trazgnies Granda, señaló de manera explícita que:
}

Y ahora Perú y Chile ponen fin a las últimas secuelas con las que los hechos del pasado intentaron, vanamente, marcar con sangre nuestro futuro. Y es así, como podremos entrar, dentro de dos meses, al siglo XXI libres de las hipotecas morales y de las secuelas que tuvieron su origen en problemas del siglo XIX. ("Los Acuerdos entre Chile y Perú", 2000). 
momentos en que se negociaba la firma del Acta de Ejecución con Perú. Además, no se puede dejar de señalar que Pinochet en democracia, siguió ejerciendo una fuerte influencia en determinados niveles de la toma de decisión política, especialmente en temáticas relativas a la política exterior y la defensa, en su puesto de Comandante en Jefe del Ejército, cargo que detentó hasta 1998.

Mientras que por el lado peruano, la política exterior del palacio de Torre Tagle ${ }^{5}$ en los noventa, estuvo marcada por tres grandes perspectivas. En primer lugar, el autogolpe de Estado dado por el entonces Presidente Alberto Fujimori el año 1992, alteró la gobernabilidad del país, lo que también significó la maximización del poder presidencial por sobre los otros componentes del Estado. Por lo tanto, las diferentes decisiones al más alto nivel político, incluyendo aquellas vinculadas a la política exterior, tenían la visión del mandatario aludido. Por dicha forma de concebir la política, para muchos autores, desde dicho acontecimiento del autogolpe, Perú cayó en una dictadura, lo que a su vez le trajo problemas de reconocimiento y aislamiento internacional, aunque por un breve periodo (Rodríguez, 2004).

Sumado a lo anterior, emergen dos acontecimientos altamente relevantes, y que influyeron en la manera en que se gestionó la política exterior de Perú. Por un lado, se tuvo el conflicto bélico que mantuvo dicho país con Ecuador en la zona del Alto Cenepa, en el año 1995; y por otro lado, también se considera como un proceso clave, la fuerte irrupción de grupos terroristas que atentaban en contra de la estabilidad institucional del país, como lo fueron Sendero Luminoso o el Movimiento Revolucionario Túpac Amaru (MRTA). Estos dos sucesos, no solamente limitaron el accionar de la política exterior peruana, sino que también la concentraron en focos de acción muy puntuales, especialmente en lo relativo a dar una solución a la diferencia territorial con Ecuador (García, 2015). Por lo tanto, un acercamiento entre Chile y Perú, dadas las circunstancias de ambos países por la década de los noventa, si bien se efectuó de manera exitosa, se dejó eminentemente en un plano técnico, tomando en cuenta los diferentes procesos a los cuales se enfrentaban ambos países.

Es así como producto de aquellos aspectos, una vez iniciado el nuevo milenio, las relaciones entre Chile y Perú comenzaron a retomar una lógica conflictiva, como consecuencia de que los aspectos que limitaban el accionar de ambas cancillerías, se habían resuelto. Por el lado chileno, la influencia militar en ciertos sectores decisionales ya no era una realidad, añadiendo además una fuerte influencia de la visión económica-comercial en la política exterior chilena, la que tuvo un nuevo impulso a través de la suscripción de tratados de libre comercio (TLC), tanto con países como Estados Unidos como con la Unión Europea. Mientras que por el lado peruano, la excesiva influencia de las decisiones presidenciales en ciertos aspectos políticos y sociales, como lo fue durante la administración Fujimori, había dado paso a un periodo de transición política, con la abrupta salida del país del mencionado mandatario. Con ello, instituciones como la cancillería, retomaron la agenda propia de una política de Estado, en detrimento de la posición autoritaria del anterior mandatario (Basombrio y Rospigliosi, 2006). Y al mismo tiempo, tanto el conflicto con Ecuador, como la insurrección interna de los movimientos que utilizaban el terror para son el logro de sus objetivos políticos, eran aspectos que si bien aún estaban frescos en la memoria colectiva, ya formaban parte de una agenda realizada.

\footnotetext{
${ }^{5}$ Cabe señalar que se le denomina "Torre Tagle" a la Cancillería del Perú.
} 
Es así como ambos países, al iniciar el siglo Xxi, si bien consideraban que tenían una agenda de futuro con "temas cerrados", aquello no resultó así, como consecuencia de los elementos mencionados. En este plano, el hecho de que los países manifestaran a través de diferentes instrumentos, si bien produjo un acercamiento entre las partes, lo cierto es que los elementos estructurales no se tocaron dentro de las diferentes negociaciones. Y dentro de aquellos aspectos estructurales, estaban los concernientes a las diferencias de interpretación sobre una serie de espacios territoriales, los que adquieren una importancia dentro de la agenda bilateral son el tema de la delimitación fronteriza marítima, y posteriormente a aquello, la soberanía por la zona territorial denominada "triángulo terrestre".

\section{La controversia por la delimitación marítima y sus aspectos subyacentes}

Como consecuencia del contexto señalado es que, a inicios del siglo xxi, ambos países se vieron enfrentados en torno a las posiciones sobre la existencia, o no, de una frontera marítima, como también a diferencias de interpretación con respecto al inicio de la frontera terrestre. Aunque en este último punto, la diferencia comenzó luego de conocer el fallo del alto tribunal internacional. Con respecto a la controversia por la frontera marítima, es posible mencionar que el primer antecedente al respecto se remonta al año 1986, con la redacción del denominado "Memorándum Bákula", haciendo una directa alusión al autor de dicho documento, el entonces embajador del Perú en Chile, Juan Miguel Bákula, dirigido al canciller chileno de la época, Jaime del Valle (Bákula, 2002). Sin embargo, pasada la década de los noventa, y por los motivos señalados, dicha perspectiva no fue considerada como tal, especialmente desde la óptica oficial de la política exterior chilena. Aquella lógica finalizó luego de dos acontecimientos en particular. El primero, fue el depósito en Naciones Unidas de una carta náutica chilena, en la que se establecía la frontera marítima con Perú, en octubre de 2000. Este suceso fue reclamado oficialmente por Perú, presidido en aquel entonces por el gobierno de transición de Valentín Paniagua, el cual señaló que no reconocía la existencia de un límite marítimo entre las partes, dejando constancia de ello en Naciones Unidas (Sifuentes y Riepl, 2014). Mientras que el segundo acontecimiento fue lo que se conoce como el conflicto de "la caseta". Este percance bilateral se resume al movimiento que efectuó la Armada de Chile de una caseta de vigilancia que se encontraba cercana al límite terrestre y marítimo entre ambos países. Este movimiento fue reclamado oficialmente por Perú, señalando que la caseta había sido trasladada a territorio peruano, por lo que se exigía su restitución a territorio chileno. Chile señaló oficialmente que la caseta había sido trasladada dentro de territorio chileno. Finalmente, la Armada de Chile recibió la orden de trasladar nuevamente la caseta al lugar original (Rodríguez, 2006).

Más allá de entrar en la descripción de los antecedentes que llevaron a la generación de la controversia jurídica por el límite marítimo, se destaca de los dos acontecimientos señalados, que la concepción territorial como problema entre ambos países, pese a las señales enviadas a fines de la década de los noventa, eran reales y palpables. Más aún, tomando en consideración el hecho de que en el periodo de Fujimori, el cual se considera como un gobierno autoritario en múltiples sentidos (Basombrio y 
Rospigliosi, 2006; Murakami, 2012), los vínculos generados en la relación bilateral, especialmente en términos de integración comercial, se mantenían, la agenda conflictiva no fue tocada. Y si aquello sucedió, como con el Acta de Ejecución de 1999, fue en un sentido técnico. Al respecto, la concepción de "conflicto territorial" en el siglo XXI, como consecuencia de los mencionados sucesos, fue nuevamente tomando cabida en la agenda bilateral, lo que a su vez dio como resultado la instauración de imágenes y discursos que reforzaban dichos relatos, los cuales varían dependiendo del país que los formule.

Desde el punto de vista chileno, la "reapertura" de un conflicto territorial, el cual parecía cerrado, tuvo consecuencias en la forma de concebir la política exterior de Perú hacia el país, de una manera diferente a la que se tenía en la década de los noventa. Así, para la política exterior chilena, el caso de la disputa por la delimitación de la frontera marítima, era un caso "construido" por Perú, lo que a su vez estableció un relato sobre dicho país en torno a una política "revanchista" hacia Chile (Milet, 2005). Lo anterior, además, era apoyado por una serie de problemas que se comenzaron a producir hasta la demanda misma que, si bien no estaban relacionados directamente con el problema en cuestión, generaban tensiones entre las partes, como por ejemplo lo sucedido con la instalación de la planta de la empresa de capitales chilenos Lucchetti, en una zona que de acuerdo al municipio de la ciudad de Lima, eran zonas naturales protegidas, y los datos sobre la venta de armas por parte de Chile a Ecuador, en pleno conflicto de este último país con Perú, siendo Chile país garante del Protocolo de Rio de Janeiro.

En otro sentido, para la visión peruana, la controversia en lo relativo a la frontera marítima, no fue un tema construido como lo planteaba su contraparte chilena, debido a que había un antecedente claro y formal en la década de los noventa que manifestaba aquella discrepancia. Pero dicha posición va más allá. La negativa chilena de no coincidir en los puntos en los cuales se tenían diferencias por la frontera marítima, en especial la posición de "no negociación" de parte de Chile, estableció una concepción sobre el país mencionado vinculado a un "expansionismo" del mismo, lo que también tuvo elementos que apoyaban dicha posición. Un ejemplo de lo anterior es la demanda interpuesta por tribunales chilenos sobre la empresa de capitales peruanos Aerocontinente, como también la perspectiva de que la línea aérea de capitales chilenos LAN, fuera la principal empresa de transporte aéreo en el país (Milet, 2005).

Ahora bien, cabe señalar que la demanda marítima por la definición de los límites entre ambos países, si bien se manejó principalmente dentro de los canales diplomáticos, los elementos subjetivos y geopolíticos de la misma, no solamente se representaban a través de un nuevo trazado de la frontera, sino que involucraban otros aspectos. Algunos de ellos eran, por ejemplo, la proyección que cada país podía realizar en diferentes espacios marítimos, la primacía de sus puertos en un eventual detrimento de la contraparte, como también la noción histórico-política subyacente de los territorios "recuperados". En este sentido, es posible también encontrar elementos que dan cuenta de que el problema si bien se manifestaba en el posicionamiento de cada país en torno a la delimitación de la frontera marítima, había aspectos subyacentes que se encontraban vinculados a la causa, pero no de forma explícita. Así, dichos elementos se vinculan principalmente con la representación geopolítica que se tenía tanto de parte de cada uno de los países involucrados en la controversia, como también hacia la contraparte (Kahhat, 2008). 
Uno de los puntos en los cuales los dos países chocaban - y siguen chocando-, fue en lo relativo a la proyección que sus puertos poseen, como también a la visión de un estado de control sobre las rutas comerciales marítimas y terrestres, especialmente en dirección al Asia Pacífico. Es así como a nivel oficial, se comenzó a construir un discurso en torno a la visualización de los países en cuestión, sobre la base de lo mencionado. Para el caso chileno, el país debía ser considerado como un "país puente", en lo que respecta a los mercados asiáticos y las rutas comerciales que los relacionaban a países suramericanos ribereños del océano Atlántico. Mientras que para Perú, que también poseía una concepción similar, se señalaba que el país debía convertirse en un "país pivote", debido a su conexión tanto con cuencas hídricas que tenían directa vinculación con países del Atlántico, como también por su posición geográfica al centro del continente suramericano. Esto, para demostrar su posicionamiento beneficioso en relación con los grandes mercados de la región del Asia Pacífico. Así, dichas posiciones si bien fueron establecidas de manera oficial por ambos países a través de diferentes instrumentos, su principal manifestación fue a través de la generación del conflicto de la delimitación marítima, como una manera de mejorar dicha ubicación geopolítica, al tiempo que se minimiza a la de la contraparte (Cabrera, 2010).

Uno de los elementos que se visualizan dentro de los discursos académicos en el contexto de la controversia por la frontera marítima, es el hecho de que la visión de la contraparte en lo relativo al territorio en disputa, tiene una concepción principalmente centralista. El hecho de que las nociones de frontera se interpreten desde la centralidad del Estado, minimiza el impacto que tiene el territorio para las poblaciones que son parte de él. Así, una eventual derrota, era interpretada como un juego de suma cero, en donde el territorio se representaba con una significación de poder en términos absolutos. Lo cierto es que la perspectiva centralista del territorio, no permite concientizar ni comprender la importancia de la frontera como un espacio de interacción y comunicación entre países y sociedades. Es por ello que una serie de autores, en ambos países, si bien establecieron la relevancia de socializar la disputa marítima en las zonas que eran directamente afectadas, dicho enfoque fue minimizado, o en su defecto, no fue debidamente comprendido, producto de que las explicaciones tenían una lógica proveniente desde la centralidad del Estado (Ovando y Zapata, 2016). Este aspecto, es decir la interpretación centralista del problema territorial, puede concebirse como un ejemplo de la noción clásica de la geopolítica, mientras que el reconocimiento de otras realidades culturales que intervienen en la representación del territorio, puede ser visto como un caso de análisis derivado de la concepción crítica de la geopolítica.

Pero pese a que ambos países reconocieron que existía un problema bilateral, el cual era la delimitación de la frontera marítima, este a su vez estableció otra problemática que no se tenía necesariamente contemplada en la agenda bilateral, la cual era la diferencia por el inicio de la frontera terrestre, lo que se conoce como el "triángulo terrestre". Y pese a que si bien este proceso se considera como una parte más de la controversia antes señalada, aquello no es así, debido a la naturaleza misma del proceso terrestre, la interpretación que se le da por ambas partes, como también por los mecanismos que implicaría su solución si no se llega a un acuerdo mutuo. 


\section{El "triángulo terrestre": Otro tema, otra agenda}

La noción que se maneja del otro problema territorial, y que en la actualidad se encuentra pendiente en torno a la definición del inicio del punto en el cual se inicia la frontera terrestre desde el mar, lo que se conoce comúnmente como el "triángulo terrestre", tanto para chilenos como para peruanos, posee una connotación diferente, especialmente en lo que representa. En primer lugar, si bien es cierto que puede considerarse una temática adyacente a la controversia que ambos países sostuvieron con respecto a la delimitación marítima, su gestión es totalmente diferente, e incluso, la misma CIJ no se pronunció al respecto. Y en segundo lugar, al ser parte de una diferencia en el plano terrestre, las connotaciones y visiones que se tienen al respecto, difieren del problema marítimo, por el simple hecho de estar ubicado en una dimensión territorial distinta (Kahhat, 2017).

$\mathrm{Al}$ respecto, existen diferencias incluso al origen de dicha controversia. Si bien es cierto que se tenía como antecedente el problema de "la caseta", y que incluso se le solicitó a la cij que fijara el punto de inicio de la frontera marítima, este aspecto solamente se tocó en un punto mínimo, debido a su naturaleza diferente. Así, el problema no necesariamente nace de la controversia en sí, sino que, para algunos autores, nace de manera posterior a la controversia por el límite marítimo, específicamente por las palabras pronunciadas por el entonces Presidente de Chile, Sebastián Piñera, momentos previos de conocerse el fallo de Corte mencionada (Wieland, 2014). La interpretación que le dio el mandatario señalado, tuvo una respuesta del Estado peruano, señalando el problema de interpretación sobre dicha zona geográfica. Por ende, si bien había antecedentes sobre problemas en la demarcación de la soberanía en dicho espacio territorial, no fue sino hasta después del fallo por la delimitación de la frontera marítima, que dicha controversia se instaló en la agenda.

No obstante, y pese al claro vínculo que tiene este problema con el de la delimitación marítima, sus naturalezas son diferentes. La frontera terrestre entre ambos países fue un proceso altamente complejo, e involucra elementos que se relacionan directamente con las consecuencias del conflicto bélico sostenido en la segunda mitad del siglo xix entre ambos países. Incluso, la negociación de la frontera terrestre, como se mencionó en su momento, duró 50 años, y dio paso a una serie de complejidades que incluso tuvieron a los dos países cerca de un nuevo conflicto bélico (González, 2008). Mientras que el tema de la frontera marítima, si bien puede ser también considerado como una consecuencia de la guerra, la forma en que ambos países la gestionaron, incluso en los documentos oficiales presentados a la CIJ, no se advierte una visión de aquel pasado conflictivo del siglo xix. Incluso, las negociaciones entre ambas partes por el establecimiento de límites marítimos, se inicia a mediados del siglo xx, aunque tuviesen un alcance y aplicabilidad reducida. Por lo tanto, puede considerarse que la problemática marítima es mucho más contemporánea que la terrestre, y tuvo menos problemas en su gestión.

Al ser un problema que tiene su raíz en la interpretación de uno de los puntos del Tratado de Lima de 1929, lo cierto es que la complejidad también se da desde la significación de lo que representa dicho instrumento para las partes, el cual sería el establecimiento definitivo de la frontera común. Sin embargo, aunque en este ámbito es compartido por el discurso oficial en cada país, lo cierto es que la significación que tiene para Perú, es muy diferente a la que puede poseer Chile, por el hecho 
de ser el primer país el que perdió territorios a costa del segundo. Así, la noción de abrir un tema cerrado, no solamente generaría como consecuencia la recuperación y maximización de imágenes negativas del pasado, sino que además reforzaría la visión de que, desde la perspectiva chilena, siempre habrá temas pendientes con el país vecino del extremo norte, debido a la existencia y no superación de un "trauma territorial", y específicamente hacia Chile (Leyton, 2007). Pero como se señaló, la perspectiva peruana lleva consigo un aspecto que no es menor, y es la sensación de pérdida territorial, con toda la carga emocional y simbólica que ello establece, tanto como respuesta a lo que fue la ocupación chilena, y el hecho de que dichos territorios fueron peruanos (Mc Evoy, 2016). Por ende, pese a que sea un territorio en términos espaciales pequeño, su significación simbólica es directamente lo opuesto, debido a que es un espacio territorial que tiene una relación directa con las consecuencias de la Guerra del Pacífico o del Salitre, especialmente para Perú.

Pero existe otro aspecto que diferencia estas interpretaciones territoriales, en comparación a la que sostuvieron ambos países en la cIJ, y es que producto de que es un problema que se encuentra dentro de los términos estipulados en el Tratado de 1929, las dificultades y controversias se dirimen de una forma diferente. El mismo texto indica de manera explícita, que si hubiese discrepancias en alguno de los puntos que consta en el tratado, la autoridad para dirimir aquello es el presidente de los Estados Unidos. Precisamente, aquel ha sido uno de los puntos que las partes consideran clave y que, como consecuencia de la coyuntura política que posee en la actualidad el país señalado, se ha visualizado que incluir a un tercer actor en dicha controversia, no se vislumbra como algo posible y que, de alguna forma, no sería conveniente para el interés de ambas partes. Eso marca un claro contraste a lo que fue el proceso judicial en la CIJ, en donde si bien había un árbitro, este se enmarcaba dentro de procesos internacionales en los que las partes podían intervenir bajo un determinado esquema.

La problemática de la representación territorial, es que la concepción del "triángulo terrestre" posee una vinculación directa con el pasado conflictivo con una mayor ponderación que la controversia por la delimitación marítima. Es por ello, que puede entenderse que el discurso conflictivo por el espacio territorial terrestre, no haya solamente tenido un manejo diferente de parte de las autoridades encargadas de la planificación y elaboración de la política exterior, sino que también desde el mundo académico (Rodríguez, 2014). En este sentido, el "triángulo terrestre" ha sido considerado desde dos grandes perspectivas: el valor mismo del territorio en términos de dimensión geográfica; y como el elemento que no permitiría a ambos países avanzar en las relaciones bilaterales, luego de haber finalizado un proceso jurídico internacional por una controversia territorial. El "triángulo terrestre" es un problema diferente al de la frontera marítima, por la dimensión territorial que involucra, y la proyección que puede generar un territorio así para cualquiera de los dos países, es mínima. Esta interpretación coloca a la diferencia territorial en una prioridad diferente, lo que sumado a que se le otorga una connotación directamente ligada a las consecuencias de la guerra de 1879, da cuenta de un problema de mayor complejidad, tanto política como socialmente (Roncagliolo, 2017). Y en segundo término, la continuación de un problema territorial, generaría una tendencia a "territorializar" la agenda bilateral, volviendo con ello a una lógica de "cuerdas separadas", propia del comienzo del proceso en la CIJ en el año 2008 (García-Corrochano, 2012). 
Pero sin perjuicio de las dos disputas territoriales que se han destacado, existe un aspecto que no puede dejar de señalarse y es que las partes han establecido diversos mecanismos, en diferentes niveles, para poder revertir aquella tendencia negativa de los conflictos territoriales, y poder avanzar en otros aspectos de la agenda bilateral. Pero lo cierto es que si bien ha habido avances, estos no quedan ajenos a los temas que se pueden considerar estructurales en la relación, como lo son aquellos relacionados a las disputas territoriales. Es por eso que es posible visualizar que, más allá de determinados esfuerzos, la relación tiene esquemas de vinculación conflictivos de características estructurales, que van más allá de la coyuntura.

\section{Un problema estructural}

Es un hecho que dentro de la relación bilateral Chile-Perú, la historia posee una gran influencia en lo que ha sido la generación de una determinada imagen, como también en su mantención y refuerzo a lo largo de los años, especialmente en lo que concierne a una concepción negativa de la contraparte. Al respecto, las visiones del ganadorperdedor de la Guerra del Pacífico, si bien se manifiestan con mayor fuerza en los relatos históricos de Chile y Perú respectivamente, dichos relatos no solamente se constituyen como un acontecimiento más, sino que son parte de la generación de una identidad nacional (Parodi, 2010; Villalobos, 2002). Es producto de la reproducción de dicho relato histórico, que no solamente se han definido las actuales fronteras entre los dos países, sino que además se han establecido héroes, sucesos puntuales y representaciones sobre la contraparte, que se han derivado, casi de manera exclusiva, de la Guerra del Pacífico o del Salitre. Este proceso no es menor, ya que si bien es cierto que se reconoce la importancia que para la historia bilateral es el conflicto bélico señalado, también es necesario mencionar que una buena parte de la agenda conflictiva, especialmente cuando se trata de un tema territorial en disputa, se alimenta de las consecuencias de aquella guerra, incluso en el presente.

Relacionado con lo anterior es que visualizando el relato histórico conflictivo, se aprecia una interpretación de una serie de acontecimientos del pasado, bajo los ojos de la influencia del conflicto bélico de 1879. Por ejemplo, si bien es cierto que la historia de la relación bilateral Chile-Perú no nace con aquella guerra, la mayoría de los acontecimientos que sucedieron antes de aquel conflicto han sido reinterpretados como una manera de acrecentar las diferencias históricas, al tiempo de servir de argumentos en torno a que el conflicto entre ambos países, no fue un aspecto puntual en la historia (González y Parodi, 2014). Al respecto, es posible considerar dos ejemplos. El primero, se relaciona con la gesta que organizaron de manera conjunta Chile y Perú, además de otros países entonces ribereños de la costa del océano Pacífico sur, en contra de España entre los años 1864 y 1866. Este acontecimiento, que fue un ejemplo histórico de la unión suramericana en la defensa de intereses comunes, ha sido interpretado como una manera de separar esfuerzos, así como también un antecedente directo de la guerra de 1879. Y el otro acontecimiento fueron precisamente los tratados internacionales de 1952 y 1954, los que si bien se pusieron en tela de juicio en el siglo xxi sobre si eran o no instrumentos que establecían la frontera marítima entre Chile y Perú, cabe señalar que la naturaleza y espíritu de los mismos eran de plena integración. Así, dichos tratados se suscribieron para proteger 
a Chile, Perú y Ecuador de las acciones que llevaban a cabo empresas transnacionales, depredando los recursos naturales que se encontraban en aguas cercanas a sus costas. Pero ambos relatos, o bien han sido interpretados de una forma negativa, o en su defecto, no se ha reconocido la naturaleza de los mismos como acontecimientos positivos en la historia de la relación.

Dicha visión negativa ha tenido un impacto dentro de las sociedades. Y es en este punto donde, a juicio de José Miguel Flórez (2007), se percibe la mayor diferencia. Es así que, si bien los países pueden hacer esfuerzos en tratar de minimizar la concepción negativa de los acontecimientos, aquellos esfuerzos son meramente coyunturales, debido a que "el problema" se encuentra radicado en la sociedad. La percepción negativa se manifiesta en diferentes actos y discursos sociales, como consecuencia de los elementos señalados. Y pese a los eventuales acercamientos oficiales que se puedan tener en torno a la construcción de parámetros de diálogo y acercamiento, la desconfianza ha sido construida a lo largo de los años dentro de las sociedades, lo que incluso se manifiesta en actos oficiales por parte de ambos países, como lo son los procesos conflictivos territoriales mencionados en su momento.

El discurso académico y las posiciones geopolíticas que se pueden extraer de los mismos, si bien establecen nuevos parámetros y procesos sobre los cuales se visualizan nuevas perspectivas en la relación, se encuentra centrado en los factores que son parte de aquella conflictividad estructural, tomando a las disputas territoriales como elemento central. Siendo así, la conflictividad tiene un papel altamente relevante en la discusión sobre las relaciones bilaterales, pero destacando el hecho de que el relato sobre la contraparte, si bien se construye sobre la conflictividad territorial, también se ha generado el proceso de que se han efectuado una serie de acercamientos producto de las diferencias. Tal vez uno de los principales ejemplos fueron los acercamientos académicos y en diferentes áreas del quehacer de ambos países, promovido por la Fundación Konrad Adenauer, lo que dio como resultado que diferentes actores, tanto chilenos como peruanos, intercambiaran puntos de vista sobre el contexto de la relación bilateral, como también experiencias en sus respectivas actividades (Guerra, 2014). Y otro de los ejemplos en los que la construcción de un discurso oficial, pero que generó consecuencias geopolíticas positivas para la relación entre ambos países, fue el establecimiento de la política de "cuerdas separadas", la que se elaboró el año 2008, de manera posterior a la presentación de la demanda peruana en contra de Chile en la cIJ. Con ello, se deseaba conservar un canal de diálogo, con el principal objetivo de mantener los fuertes vínculos comerciales que poseen ambos países, al tiempo que se dejaba el tema de la delimitación marítima a los designios del alto tribunal internacional (Vidarte, 2017).

Por lo tanto, la concepción estructural del problema, si bien se ve reflejada en el discurso académico, también es cierto que la visión conflictiva se minimiza, al tiempo que aparecen y se visibilizan nuevos procesos y actores que intervienen en la relación. Sin embargo, el discurso oficial como también que proviene de otras fuentes, como por ejemplo los medios de comunicación masivos, poseen un grado de interferencia que logran construir, y mantener, una concepción negativa de la relación bilateral en su conjunto. Y aquella percepción se ve reforzada al momento en que surge la visión de la contraparte, es decir Chile o Perú, dentro de una disputa territorial. Por lo tanto, si bien el discurso establece una realidad social, aquella se deriva directamente de la concepción conflictiva en lo relativo al territorio y la significación que este elemento posee para un sector relevante de la sociedad, tanto en Chile como en el Perú. 


\section{Conclusiones}

La relación Chile-Perú, como toda relación bilateral que posee el componente de frontera común entre aquellos países, es una relación compleja; pero a diferencia de otras realidades donde los países que han experimentado experiencias negativas y han generado al mismo tiempo espacios de confianza y cooperación a un alto nivel, para la relación bilateral esbozada, aquello no se ha dado, especialmente en lo relativo a los aspectos "sensibles" de la misma, como lo son los conflictos que se vinculan, en mayor o menor medida, a los temas territoriales. Es cierto que es posible evidenciar que la relación en la actualidad, posee fuertes componentes de cooperación e integración, especialmente en lo que respecta a la comunicación transfronteriza, como también en un sentido del creciente intercambio comercial. Sin embargo, dichos aspectos aún se encuentran supeditados a los temas "sensibles", como se señaló en su momento.

$\mathrm{Al}$ respecto, conviene señalar que si bien los países han buscado una gestión dentro de los medios pacíficos que el sistema internacional provee para resolver las disputas, como lo fue la misma demanda en la ciJ, lo cierto es que aquello es resolver una parte de la problemática, más no necesariamente el origen de la misma. Los problemas de aquellas cualidades, es decir desavenencias territoriales con un fuerte componente geopolítico subyacente, no se resuelven con el fallo de un tribunal o por un acuerdo al más alto nivel político. El proceso de resolver dichas problemáticas involucra a actores que van más allá del Estado como institución, así como también a diferentes niveles de la sociedad y no solamente concentrando aquella visión en un segmento reducido de la misma, como lo son los tomadores de decisión en el ámbito de la política exterior. Los problemas subyacentes en la relación Chile-Perú, poseen un fuerte componente social que no debe dejarse de considerar.

Pero el problema no solamente está en la falta de incorporación de otros sectores de la sociedad, sino que en la incapacidad de reconocer la importancia de los elementos conflictivos subyacentes, como parte de una problemática mayor. Este es, tal vez, uno de los puntos de mayor dificultad en la construcción de un proceso de acercamiento real y fidedigno entre las partes, debido tanto al costo político que puede acarrear, como también al espacio de tiempo que puede tomar en generar dichas condiciones. Pero para reconocer aquellos elementos conflictivos subyacentes, se requiere de otras visiones analíticas y explicativas, que permitan no solo evidenciar la relevancia de aquellos aspectos, sino que también su visualización y conocimiento, tanto en los sectores o niveles donde se toman las decisiones de política exterior, como también a nivel de sociedad. Por lo tanto, se requiere también una renovación de la comprensión de los conflictos territoriales, que vaya más allá de las concepciones positivistas clásicas, como lo es la geopolítica clásica o, en su defecto, del Estado absoluto y monolítico en términos de poder soberano. $\mathrm{Y}$ es en este punto donde el discurso académico puede tener un aporte relevante para la mejora de las relaciones, desde un punto de vista estructural.

Si aquel proceso no se logra, lo más probable es que se tenga una repetición de lo sucedido a fines de la década de los noventa entre ambos países, en donde si bien se declaraba de manera oficial un discurso de "heridas cerradas", no se contemplaba un proceso mucho más amplio y estructural de generación de confianza y conocimiento mutuo. Por lo tanto, si aparece en el futuro una nueva discrepancia, el no contar con el proceso mencionado, generará como consecuencia que los fantasmas del pasado 
nuevamente involucren a la totalidad de la relación, reafirmando la relevancia de estos tópicos por sobre las múltiples áreas de acercamiento y cooperación que pueden, y deben existir, entre chilenos y peruanos.

\section{Referencias}

Agnew, J. (1994). The territorial trap: The geographical assumptions of international relations theory. Review of International Political Economy, 1(1), 53-80.

Anderson, M. (1996). Frontiers. Territory and State formation in the modern world. Oxford, Reino Unido: Polity Press.

Bákula, J. M. (2002). Perú: Entre la realidad y la utopía. 180 años de política exterior. Lima, Perú: Fondo de Cultura Económica, Fundación Academia Diplomática del Perú.

Basombrio, C. y Rospigliosi, F. (2006). La seguridad y sus instituciones en el Perú a inicios del siglo XXI. Reformas democráticas o neomilitarismo. Lima, Perú: Instituto de Estudios Peruanos.

Cabrera, L. (2010). Chile-Perú: Discursos contrapuestos y sus manifestaciones geopolíticas. ICONOS. Revista de Ciencias Sociales, (38), 95-104.

Cabrera, L. (2017). Geopolítica en América del Sur: Desde la militarización de la disciplina a la necesidad del debate académico. Revista Chilena de Derecho y Ciencia Política, 8(2), 165-186.

Cairo, H. y Lois, M. (2014). Geografía política de las disputas de fronteras: Cambios y continuidades en los discursos geopolíticos en América Latina (1990-2013). Cuadernos de Geografía, Revista Colombiana de Geografía, 23(2), 45-67.

Child, J. (1979). Geopolitical thinking in Latin America. Latin American Research Review, 14(2), 89-111.

Cohen, S. B. (2015). Geopolitics. The geography of international relations. Nueva York, Estados Unidos: Rownman \& Littlefield.

Cuéllar, R. (2012). Geopolítica: Origen del concepto y su evolución. Revista de Relaciones Internacionales de la UNAM, (113), 59-80.

Dalby, S. (1990). Creating the Second Cold War. The discourse of politics. Londres, Reino Unido: Pinter Publishers.

Dodds, K. J. (1993). Geopolitics, cartography and the State in South America. Political Geography, 12(4), 361-381.

Dodds, K., Kuus, M. y Sharp, J. (2013). Introduction: Geopolitics and its Critics. En K. Doods, M. Kuus y M. Sharp (Eds.), The Ashgate Research Companion to Critical Geopolitics (pp. 1-14). Londres, Reino Unido: Ashgate Publishing.

Fermandois, J. (2004). Mundo y fin de mundo: Chile en la política mundial 1900-2004. Santiago, Chile: Universidad Católica de Chile.

Flórez, J. M. (2007). El viaje interior. La dinámica social peruana y el 'problema chileno'. En M. Artaza y P. Milet (Eds.), Nuestros vecinos (pp. 399-415). Santiago, Chile: RIL Editores.

García, J. (2015). Política exterior y diplomacia peruana: Pasado, presente y futuro. En F. Novak y J. García (Coords.), La política exterior peruana en el siglo xxI: Agenda y propuestas (pp. 39-50). Lima, Perú: Instituto de Estudios Internacionales, Pontificia Universidad Católica del Perú, Fundación Konrad Adenauer Stiftung. 
García-Corrochano, L. (2012). La política exterior del Perú respecto de Bolivia y Chile 1992-2012. En F. Novak (Coord.), Veinte años de política exterior peruana (19912011) (pp. 75-94). Lima, Perú: Pontificia Universidad Católica del Perú.

González, S. (2008). La llave y el candado. El conflicto entre Perú y Chile por Tacna y Arica (1883-1929). Santiago, Chile: Lom ediciones.

González, S. y Parodi, D. (2014). Introducción. En S. González, y D. Parodi (Coords.), Las Historias que nos unen. Episodios positivos en las relaciones peruano-chilenas, siglos XIX y XX (pp. 15-24). Santiago, Chile: RIL editores, Universidad Arturo Prat.

Guerra, H. (2014). Grupo Generación de Diálogo Perú-Chile / Chile-Perú: Tres años de construcción de confianza. Agenda Internacional, xxI(32), 127-149.

Hassner, R. E. (2006-2007). The path to intractability time and the entrenchment of territorial disputes. International Security, 31(3), 107-138.

Kahhat, F. (2008). Tras la Guerra Fría. Mentalidad militar y políticas de seguridad en Sudamérica. Lima, Perú: Fondo editorial del Congreso del Perú.

Kahhat, F. (2017). Lecciones del proceso entre Chile y Perú ante la Corte Internacional de Justicia. En A. Panfichi y E. Venero (Coords.), La frontera disputada. La ruta a la sentencia de La Haya (pp. 29-42). Lima, Perú: Pontificia Universidad Católica del Perú.

Kelly, P. (2006). A critique of critical geopolitics. Geopolitics, 11(1), 24-53.

Kelly, P. (2016). Classical geopolitics. A new analytical model. Stanford, Estados Unidos: Stanford University Press.

Lacoste, Y. (2011). Las etapas de la geopolítica. En L. A. González (Coord.), Cuaderno de Trabajo. Antología. Los principales autores de las escuelas de la geopolítica en el mundo (pp. 11-22). México: Universidad Nacional Autónoma de México, Gernika.

Leyton, C. (2007). Amigos y vecinos en la costa del Pacífico. Luces y sombras de una relación. Santiago, Chile: Academia Nacional de Estudios Políticos y Estratégicos.

Los Acuerdos entre Chile y Perú sobre el Tratado de Lima de 1929. (2000). Fuerzas Armadas y Sociedad, 15(1), 49.

Mc Evoy, C. (2016). Guerreros civilizadores. Política, sociedad y cultura en Chile durante la Guerra del Pacífico. Lima, Perú: Pontificia Universidad Católica del Perú.

Milet, P. (2005). Chile-Perú: Las raíces de una difícil relación. Estudios Internacionales, 38(150), 59-73.

Milet, P. (2012). La política exterior de Chile: Enfoque histórico, 1990-2010. En M. Artaza y C. Ross (Eds.), La política exterior de Chile, 1990-2009. Del aislamiento a la integración global (pp. 315-332). Santiago, Chile: RIL Editores, Universidad de Santiago de Chile.

Müller, M. (2008). Reconsidering the concept of discourse for the field of critical geopolitics: Towards discourse as language and practice. Political Geography, 27(3), 322-338.

Murakami, Y. (2012). Perú en la era del chino. La política no institucionalizada y el pueblo en busca de un salvador. Lima, Perú: Instituto de Estudios Peruanos.

O'Tuathail, G. (1996). Critical geopolitics. The politics of writing global space. Londres, Reino Unido: Routledge.

O'Tuathail, G. y Agnew, J. (1992). Geopolitics and discourse: Practical geopolitical reasoning in American Foreign Policy. Political Geography, 11(2), pp. 190-204. 
O'Tuathail, G. y Dalby, S. (1998). Introduction: Rethinking geopolitics: Towards a critical geopolitics. En G. O’Tuathail y S. Dalby (Eds.), Rethinking Geopolitics (pp. 1-15). Londres, Reino Unido: Routledge.

Ovando, C. y Zapata, A. (2016). Hitos de integración fronteriza entre las ciudades de Tacna y Arica. En P. Milet y F. Novak (Eds.), Desafios en la relación entre Chile y el Perú (pp. 119-128). Lima, Perú: Konrad Adenauer Stiftung, Pontificia Universidad Católica del Perú, Universidad de Chile.

Parodi, D. (2010). Lo que dicen de nosotros. La Guerra del Pacífico en la historiografía y textos escolares chilenos. Lima, Perú: Universidad Peruana de Ciencias Aplicadas.

Parodi, D. (2014). Conflicto y reconciliación. El litigio del Perú contra Chile en la Corte de La Haya (2008-2014). Lima, Perú: Universidad Peruana de Ciencias Aplicadas.

Rodríguez, J. (2004). Chile-Perú. El siglo que vivimos en peligro. Santiago, Chile: La Tercera Mondadori.

Rodríguez, J. (2006). Las crisis vecinales del gobierno de Lagos. Santiago, Chile: Debate.

Rodríguez, J. (2014). Historia de dos demandas: Perú y Bolivia contra Chile. Santiago, Chile: El Mercurio-Aguilar.

Roncagliolo, R. (2017). Perú y Chile 2011: Testimonio y reflexión. En A. Panfichi y E. Venero (Coords.), La frontera disputada. La ruta a la sentencia de La Haya (pp. 11-28). Lima, Perú: Pontificia Universidad Católica del Perú.

Sifuentes, M. y Riepl, M. (2014). EL último cartucho. Cómo ganamos $50.000 \mathrm{~km}^{2}$ de mar en la Corte de La Haya. Lima, Perú: Planeta.

Vidarte, O. (2017). El diferendo marítimo y la estrategia político-diplomática del Perú. En A. Panfichi y E. Venero (Coords.), La frontera disputada. La ruta a la sentencia de La Haya (pp. 71-90). Lima, Perú: Pontificia Universidad Católica del Perú.

Villalobos, S. (2002). Chile y Perú. La historia que nos une y nos separa. 1535-1883. Santiago, Chile: Editorial Universitaria.

Wieland, H. (2014). El punto Concordia y el inicio de la frontera marítima entre el Perú y Chile. Agenda Internacional, xxI(32), 51-78.

\section{Material legislativo}

Tratado de Lima y su Protocolo Complementario. (1929). Recuperado de http:// www4.congreso.gob.pe/comisiones/1999/exteriores/chile/TRALIMA.htm

Lester Cabrera

Chileno. Doctor (c) en Estudios Internacionales, Facultad Latinoamericana de Ciencias Sociales (Flacso), Ecuador. Profesor asociado del Departamento de Estudios Internacionales y Comunicación, Flacso-Ecuador. Líneas de investigación: estudios estratégicos y geopolítica. Publicación reciente: Cabrera, L. (2018). ¿Por qué los países suramericanos aún invierten en defensa? Un análisis desde la geopolítica contemporánea. Revista Estudios Hemisféricos y Polares, 9(2), 25-42. 